\title{
Prevalence of Intestinal Parasites among the Malnourished Children in Enugu, Nigeria
}

\author{
N. F. Onyemelukwe ${ }^{1}$, U. C. Maduakor ${ }^{1 *}$, C. A. Uchenna ${ }^{1}$ and U. Okongwu ${ }^{1}$ \\ ${ }^{1}$ Department of Medical Laboratory Sciences, Faculty of Health Sciences and Technology, University \\ of Nigeria, Enugu Campus, Nigeria.
}

\begin{abstract}
Authors' contributions
This work was carried out in collaboration among all authors. Author NFO designed the study and wrote the protocol. Author UCM conducted the study and drafted the manuscript. Author CAU assisted in the laboratory investigations and did the statistical analysis. Author UO managed the literature search and arranged the manuscripts. All authors read and approved the final manuscript.
\end{abstract}

Article Information

DOI: $10.9734 / A R R B / 2021 / v 36 i 730397$ Editor(s):

(1) Dr. Paola Angelini, University of Perugia, Italy.

Reviewers:

(1) Walid Saad Mousa, University of Sadat City, Egypt. (2) Amit Kumar Dutta, Amity University Jharkhand, India. Complete Peer review History: https://www.sdiarticle4.com/review-history/70193

Original Research Article

Received 01 May 2021

Accepted 02 July 2021

Published 16 July 2021

\section{ABSTRACT}

Intestinal parasitic infections (IPIs) have remained a serious challenge to developing countries. Infectious disease and nutritional deficiencies can impact adversely on the nutritional status of children. Hence, this study aimed at investigating prevalence of Intestinal parasitic infections among malnourished children in Enugu, Southeast Nigeria. It was a case-controlled study consisting of 164 malnourished children and 100 well-nourished subjects between the ages of 0-10 years whose caregivers gave their consent. Anthropometric measures were evaluated using the Gomez system of classification. Stool samples were analyzed using standard parasitological protocols. Of the 164 malnourished children 52(31.7\%), 63(38.4\%), 49(29.9\%) had mild, moderate, and severe malnutrition respectively. Five species of helminths and three species of protozoa were detected. The overall prevalence was $51.8 \%$ among the malnourished and $12 \%$ in well-nourished children. The prevalence of IPIs among the control, mild, moderate, and severe malnutrition were $12 \%$, $36.5 \%, 60.3 \%$, and $57.1 \%$ respectively. Ascaris lumbricoides ranked highest $40(37.7 \%)$ followed by Hookworm 31(29.3\%) and the least was Strongyloides stercoralis $4(3.8 \%)$ among the helminths while Cryptosporidium spp was the most prevalent protozoa 8(7.6\%) and the least was Isospora spp. 2(1.9\%). Mixed infections were detected in $3(7.5 \%)$ and $6(21.4 \%)$ among children with 
moderate and severe malnutrition respectively. Nutritional status was found to be a significant risk factor while gender and age were statistically insignificant $P=0.118$ and $P=0.455$ respectively. The study revealed that malnourished children are highly susceptible to IPIs. There is a need for integrated effort to address malnutrition and parasitic infections

Keywords: Intestinal parasites; malnourished children; Enugu; Nigeria.

\section{INTRODUCTION}

Intestinal parasites are known to cause morbidity and mortality throughout the world particularly in developing countries and in persons with comorbidities [1]. Globally, intestinal parasitic infections (IPSs) are one of the most serious health challenges of the developing world and are listed among the World Health Organization (WHO) Neglected Tropical Diseases (NTDs) [2]. Neglected Tropical Diseases form the 4th leading cause of communicable diseases and constituted 46-57 million disability-adjusted life years lost [3]. IPIs are mostly found among the poorest people $[2,4]$. Roughly 3.5 billion people are infected with intestinal parasites globally, and children are more vulnerable [5]. The parasites have become an important health problem in Sub-Saharan Africa because of poor personal and environmental hygiene, lack of education, indigence, shortage of potable water, poor health or nutritional status and warm climate conditions [5-8]. Soil-transmitted helminths (STHs) are the most common intestinal parasites [2]. In Africa over 173 million people have Ascaris lumbricoides, over 162 million with Trichuris trichiura and more than 198 million have hookworm [3,9]. Giardia lamblia, Entoamoeba histolytica are more prevalent protozoan parasities while Cryptosporidium spp. have been reported among the immunocompromised [2].

The link between the intestinal parasites especially the STHS, and malnutrition had been chronicled [2,10-11] and they frequently have the same zone spread [2]. The nutritional status of a child is the best pointer to the child's overall health condition [5]. IPIs harm the nutritional status of the infected individuals. The parasites can trigger bleeding of the gastrointestinal tract and nutrient competition which may also lead to nutrients malabsorption. There is reduced intake of food, use of protein, and inability to absorb fat. Furthermore, nutrients are wasted through vomiting, diarrhoea, and anorexia [2,10-11]. Consequently, there is remarkable effect on growth and development of children and their academic performance [2].

Malnutrition is deficiencies, excesses, or imbalances in a person's energy or nutrient intake. It is broadly classified into under nutrition and overweight. Under nutrition includes stunting (low height for age), wasting (low weight for height), underweight (low weight for age), and deficiencies of micronutrients [12]. Nutritional deficiencies and infectious diseases can negatively affect the nutritional status of children [13]. Beyond morbidity and mortality, intestinal parasites may cause malnutrition, cognitive deficiency, anemia, poor school attendance, vulnerability to infections like HIVIAIDS, and slow growth rate. They may place serious social and economic consequences on the development of a nation [3,8,14-16]. The prevalence of under nutrition and intestinal parasites differ in different countries and regions [17]

In developing countries like Nigeria, the intestinal parasite is quite common especially because of poverty, illiteracy, ignorance and cost of medical care [5]. There is a paucity of information on the prevalence of intestinal parasites on malnourished children in Enugu; most of these study areas are slums with poor socio-economic and environmental conditions that favour the presence of parasites. Previous works done had been on the prevalence of IPIs and malnutrition in school children. The study was therefore conducted to determine the prevalence of intestinal parasites among malnourished children in the Enugu Area at different levels of nutritional inadequacy, comparing this with the rate in the well-nourished segment and highlighting the need if any for a probable deworming program irrespective of the intensity of infection for high risk of children in endemic areas like Nigeria. The study will go a long way in developing suitable intervention strategies.

\section{MATERIALS AND METHODS}

\subsection{Study Design and Subjects}

It was a case-controlled study involving a total of 164 malnourished children aged $0-10$ years. Of these children 98 were seen in the out-patient clinic, children's clinic, paediatric ward, Institute of Child Health and Dietetic Department of the University of Nigeria Teaching Hospital (UNTH) Enugu; while the remaining 66 were variously 
seen at the Park-lane Hospital, Poly Clinic Asata, Health Centres of Abakpa Nike and Uwani all in Enugu. They were selected following diagnosis made by consultant paediatricians, and other clinical/ dieticians in the various clinics. Hundred age/sex-matched well-nourished children randomly chosen from the same environment assessed in the same manner by clinicians with help of dieticians were used as controls in the study. The work was done between March 2016 and December 2019

\subsection{Sample Collection}

Fresh faecal specimens were collected from the children using clean wide-mouthed screwcapped transparent bottles with necessary instructions. Such children also have not taken any form of antihelminthic therapy within at least 6 weeks. The universal containers were appropriately labelled with the subject's name, age, sex, and weight and the stool samples so collected were immediately taken to the parasitological laboratory of the University of Nigeria Teaching Hospital for analysis. Blood samples were taken for measurement of haemoglobin.

\subsection{Haemoglobin $(\mathrm{Hb})$ Measurement}

Haemoglobin levels were measured using fingerprick blood samples on a $\mathrm{Hb}$ analyzer (Hemocue $\mathrm{Hb} 301)$. Blood was drawn with microcuvette for the determination of $\mathrm{Hb}$ in $\mathrm{g} / \mathrm{dl}$. The cut of values for anaemia was World Health Organization (WHO) guidelines [18]. Anaemia was confirmed when the $\mathrm{Hb}$ level is $<11.0 \mathrm{~g} / \mathrm{dl}$ for children aged 6 to 4.9 years, $<11.5 \mathrm{~g} / \mathrm{dl}$ for children 5- 10 years.

\subsection{Parasitological Analysis}

Stool samples were analyzed according to standard parasitological protocols [18]. Samples were examined macroscopically for the presence of adult worms, mucus/blood, and microscopically first by direct smear with normal saline and then iodine preparation. Formal- ether sedimentation technique was done using the method of Allen and Ridley. Modified Ziehl Neelsen staining technique was used to examine for Cryptosporidium spp. and the Scotch tape was used for the recovery of Enterobius vermicularis ova

\subsection{Anthropometric Assessment and Nutritional Status}

Gomez's system of classification of malnutrition was used. The child's weight was compared with that of a normal child (50th percentile) of the same age. The weight of each participant was measured with a digital weighing balance to the nearest 0.1 kilograms. The measurements were done twice and the average was taken to minimize error [19].

\section{Grading}

Mild malnutrition

$75 \%-90 \%$ Weight for age

Moderate malnutrition $\quad 60 \%-74 \%$ Weight for age

Severe Malnutrition $\quad<60 \%$

$\%$ of reference weight for age $=$ (Patient Weight) X 100

(Weight of normal Child of the same age)

\subsection{Statistical Analysis}

All statistical analyses were performed using GraphPad Prism version 7.0 (GraphPad, San Diego, CA, USA). Chi-square $X^{2}$ test and Fisher's exact test (at $95 \%$ confidence intervals) were used to test for the significant difference in the prevalence of intestinal parasitic infection among malnourished and well-nourished subjects concerning age group and gender respectively. $\mathrm{P}$-value $<0.05$ is considered statistically significant.

\section{RESULTS}

In this study, 164 malnourished children and 100 well-nourished children between the ages of 0-10 years were used. Of the 164 malnourished children, 86(52.4\%) were boys and 78 (47.6\%) were girls. While in the control 54 (54\%) were males and $46(46 \%)$ were females. Most of the children were between the ages of 3-5 years.

Table 1 shows the prevalence of IPI based on age. The prevalence of intestinal parasitic infection was $12 \%$ among the control subjects and $51.8 \%$ in the malnourished children. Age group 6-8 years recorded the highest prevalence $21(63.6 \%)$ and the least was $3-5$ years $47.1 \%$. Statistically, there was no significant difference $P>0.05 X^{2}=2.616$ in the prevalence of parasitic infection according to age.

Table 2 shows the prevalence of intestinal parasitic infection according to gender. Boys had a higher prevalence of $58.14 \%$ of parasitic infection than females $44.9 \%$. For the control 
subjects, males also had a higher prevalence of $12.96 \%$ than females $10.9 \%$. There was no significant difference in the prevalence of parasitic infection according to sex $P>0.05$.

Table 3 shows the prevalence of parasitic infection according to the nutritional status. The highest number of children with moderate malnutrition was found to harbour the highest number of parasites $60.3 \%$ followed by those with severe malnutrition $57.1 \%$, those with mild nutrition was $36.5 \%$ and the least was the control subjects $12 \%$. The differences were found to be statistically significant $\mathrm{P}=0.0002$

Table 4 shows the distribution of intestinal parasites based on the nutritional status of the subjects. Ascaris lumbricoides $38.9 \%$ were found to be the most common helminths among those with moderate malnutrition followed by
Hookworm $36.1 \%$, the least was Strongyloides stercoralis $5.6 \%$. Those with mild malnutrition had more hookworm $42.1 \%$ and the least was Enterobius vermicularis. In severe malnutrition, Ascaris spp and Hookworm spp ranked highest $30 \%$ respectively followed by Cryptosporidium spp 13.3\%, Microsporum spp 10\%, and the least was Trichuris spp. Mixed infections were detected, 3(7.5\%) harboured multiple parasites among those with moderate malnutrition while $6(21.5 \%)$ had multiple parasites among those with severe malnutrition.

Table 5, shows the distribution of parasites among malnourished and well-nourished subjects according to the subject's area of residence. Obiagu ranked highest at $40.6 \%$ followed by Abakpa/Amoji Nike at 22.6\%, the least was Asata and New Haven at $7.5 \%$ respectively.

Table 1. Prevalence of intestinal parasites by age of subjects examined

\begin{tabular}{lllll}
\hline Age Groups (years) & \multicolumn{2}{l}{ Malnourished patients $\mathbf{n = 1 6 4}$} & \multicolumn{2}{l}{ Control subjects $\mathbf{n = 1 0 0}$} \\
\hline & $\begin{array}{l}\text { No } \\
\text { examined }\end{array}$ & $\begin{array}{l}\text { No(\%) with } \\
\text { infection }\end{array}$ & No examined & $\begin{array}{l}\text { No(\%) with } \\
\text { infection }\end{array}$ \\
\hline $0-2$ & 45 & $22(48.9)$ & 22 & $2(9.1)$ \\
$3-5$ & 68 & $32(47.1)$ & 47 & $5(10.6)$ \\
$6-8$ & 33 & $21(63.6)$ & 19 & $5(26.3)$ \\
$9-10$ & 18 & $10(55.5)$ & 12 & $0(0)$ \\
Total & $\mathbf{1 6 4}$ & $\mathbf{8 5 ( 5 1 . 8 )}$ & $\mathbf{1 0 0}$ & $\mathbf{1 2 ( 1 2 )}$ \\
\hline
\end{tabular}

Table 2. Prevalence of intestinal parasitic infection by gender of subjects

\begin{tabular}{lllll}
\hline Gender & \multicolumn{2}{l}{ Malnourished $\mathbf{n = 1 6 4}$} & \multicolumn{2}{l}{ Control subjects $\mathbf{n = 1 0 0}$} \\
\hline No examined & $\begin{array}{l}\text { No(\%) with } \\
\text { infection }\end{array}$ & No examined & $\begin{array}{l}\text { No(\%) with } \\
\text { infection }\end{array}$ \\
\hline Male & 86 & $50(58.14)$ & 54 & $7(12.96)$ \\
Female & 78 & $35(44.9)$ & 46 & $5(10.9)$ \\
Total & $\mathbf{1 6 4}$ & $\mathbf{8 5 ( 5 1 . 8 )}$ & $\mathbf{1 0 0}$ & $\mathbf{1 2 ( 1 2 )}$ \\
\hline
\end{tabular}

Table 3. Prevalence of parasitic infections according to nutritional status (using Gomez system of classification)

\begin{tabular}{lllll}
\hline Nutritional status & $\begin{array}{l}\text { No } \\
\text { examined }\end{array}$ & No positive (\%) & No negative (\%) & P value \\
\hline Normal & 100 & $12(12)$ & $88(88)$ & \\
Mild malnutrition & $52(31.7)$ & $19(36.5)$ & $33(63.5)$ & 0.0002 \\
Moderate Malnutrition & $63(38.4)$ & $38(60.3)$ & $25(39.7)$ & \\
Severe malnutrition & $49(29.9)$ & $28(57.1)$ & $21(42.9)$ & \\
Total & $\mathbf{2 6 4}$ & $\mathbf{9 7}(\mathbf{3 6 . 7})$ & $\mathbf{1 6 7}(63.3)$ & \\
\hline
\end{tabular}


Table 4. Distribution of Intestinal Parasites based on the nutritional status of the subjects

\begin{tabular}{|c|c|c|c|c|}
\hline Intestinal parasite & Nutritional & Status & & \\
\hline Name of parasite & $\begin{array}{l}\text { Well-nourished (No } \\
(\%)\end{array}$ & $\begin{array}{l}\text { Mild malnutrition } \\
\text { (No (\%) }\end{array}$ & $\begin{array}{l}\text { Moderate Malnutrition } \\
\text { (No (\%) }\end{array}$ & $\begin{array}{l}\text { Severe malnutrition } \\
(\mathrm{No}(\%)\end{array}$ \\
\hline Ascaris lumbricoides & $5(41.7)$ & $5(26.3)$ & $20(48.8)$ & $10(29.4)$ \\
\hline Hookworm spp & $0(0)$ & $8(42.1)$ & $13(31.7)$ & $10(29.4)$ \\
\hline Stronglyloides spp & $0(0)$ & $0(0)$ & $2(4.9)$ & $2(5.9)$ \\
\hline Trichuris trichiura & $4(33.3)$ & $4(21.1)$ & $0(0.0)$ & $0(0.0)$ \\
\hline Enterobius vermicularis & $3(25.0)$ & $2(10.5)$ & $2(4.9)$ & $3(8.8)$ \\
\hline Microsporium spp & $0(0)$ & $0(0)$ & $0(0)$ & $3(8.8)$ \\
\hline Isospora spp & $0(0)$ & $0(0)$ & $0(0)$ & $2(5.9)$ \\
\hline Cryptosporidium spp & $0(0)$ & $0(0)$ & $4(9.8)$ & $4(11.8)$ \\
\hline Total & $12(12$ & $19(11.6)$ & $41(25.0)$ & $34(20.7)$ \\
\hline
\end{tabular}

Table 5. Frequency distribution of parasites among malnourished and well-nourished subjects according to area of residence

\begin{tabular}{|c|c|c|c|c|c|c|c|}
\hline Type of Parasite & Obiagu (\%) & $\begin{array}{l}\text { Abakpa/Amoji Nike } \\
(\%)\end{array}$ & $\begin{array}{l}\text { Coal Camp } \\
(\%)\end{array}$ & $\begin{array}{l}\text { Uwani/No } \\
(\%)\end{array}$ & Asata (\%) & $\begin{array}{l}\text { New Haven } \\
(\%)\end{array}$ & TOTAL \\
\hline Hookworm spp & $7(16.23)$ & $14(58.33)$ & $3(21.43)$ & $3(33.33)$ & $2(25.0)$ & $2(25.0)$ & $31(29.25)$ \\
\hline Ascaris spp & 19 (44.19) & $4(16.67)$ & $7(50.0)$ & $4(44.44)$ & $2(25.0)$ & $4(50.0)$ & $40(37.74)$ \\
\hline Strongyloides spp & $2(4.65)$ & $0(0)$ & $2(14.29)$ & $0(0)$ & $0(0)$ & $0(0)$ & $4(3.77)$ \\
\hline Enterobius spp & $6(13.95)$ & $0(0)$ & $0(0)$ & $2(22.22)$ & $0(0)$ & $2(25.0)$ & $10(9.43)$ \\
\hline Trichuris spp & $2(4.65)$ & $2(8.33)$ & $0(0)$ & $0(0)$ & $4(50.0)$ & $0(0)$ & $8(7.55)$ \\
\hline Microsporium spp & $2(4.65)$ & $1(4.17)$ & $0(0)$ & $0(0)$ & $0(0)$ & $0(0)$ & $3(2.83)$ \\
\hline Isospora spp & $1(2.33)$ & $1(4.17)$ & $0(0)$ & $0(0)$ & $0(0)$ & $0(0)$ & $2(1.89)$ \\
\hline Cryptosporidium spp & $4(9.30)$ & $2(8.33)$ & $2(14.29)$ & $0(0)$ & $0(0)$ & $0(0)$ & $8(7.55)$ \\
\hline TOTAL & $43(100)$ & $24(100)$ & $14(100)$ & $9(100)$ & $8(100)$ & $8(100)$ & $106(00)$ \\
\hline
\end{tabular}




\section{DISCUSSION}

The WHO's course of action for children with intestinal helminths is to treat high-risk preschool and school-age children once or twice a year, depending on the prevalence [20]. This is essential in achieving morbidity control, that notwithstanding, it does not prevent re-infection. Poor nutrient intake has been shown to increase susceptibility to parasitic infections, and together they harm children's nutritional status [21]. This study is the first to be done in Enugu, examining intestinal parasitic infections (IPIs) in malnourished children. Most work had been on the prevalence of IPIs and malnutrition in school children. Of the 164 malnourished and 100 wellnourished children $31.7 \%, 38.4 \%$, and $29.9 \%$ were the prevalence of IPIs in mild, moderate, and severe malnutrition, and $12 \%$ was recorded in well-nourished children. The result showed that nutritional status was a significant risk factor $P<0.05$. The nutritional status of a child is the best pointer to the child's overall health condition [5]. IPIs harm the nutritional status of the infected individuals. They may trigger bleeding of the gastrointestinal tract and nutrient competition which may also lead to nutrients malabsorption. In our study, there was an overall prevalence of $51.8 \%$ of IPIs among malnourished children. This prevalence is higher when compared to the work done in Guinea that reported 27\% among the malnourished children [22] but lower than 58.3\% and $67.4 \%$ reported in Oshodi Lagos and Akwa Ibom respectively all in Nigeria $[5,23]$. This high prevalence may due to ignorance, lack of basic amenities, poor sanitation, poverty, inadequate access to healthcare [23]. Differences may also be due to variations in parasitological techniques, source of drinking water, family education, and personal hygiene [24].

Ascaris lumbricoides, Hookworm, Strongyloides stercoralis, Trichuris trichiura and, Enterobius vermicularis were the nematodes detected. These parasites are favoured by warm and humid climates including copious rainfall, as well as by deficient sanitary conditions such as poor sewage disposal, and absence of portable water. The presence of these helminths may also be related to the behaviour of susceptible persons whose sanitary and societal norms are very poor [24].

Ascaris lumbricoides were the most prevalent parasite detected. This aligns with the work done in Guinea [22] but at variance with what was obtained in Akwa Ibom, South-South Nigeria that reported hookworm as the most prevalent parasite [23]. Ascaris lumbricoides are known to impair nutritional status and have been found among other helminths to be associated with malnutrition in children [23,25]. The highest prevalence of Ascaris spp. may also be due to the infective stages, which are embryonated eggs, having an immense capacity to endure harsh environmental extremes. The eggs are covered with mucopolysaccharides which make them stick to a wide variety of environmental surfaces [1].

Cryptosporidium spp was the most prevalent protozoan parasite in this study with an overall prevalence of $7.7 \%$, which agrees with $7 \%$ reported in Iran [26]. The parasite has been reported among the immune-compromised [2] and it has been currently recognized globally as the leading cause of moderate to severe diarrhoea [27]. The parasite is an environmentally resistant organism. It can withstand a myriad of disinfectants, including chlorine [28]. It is one of the major concerns of physicians especially with the increasing rate of immunodeficiency. In immune-compromised patients, acute or chronic diarrhoea caused by these parasites is normally followed by weight loss, dehydration, abdominal pain, and malabsorption syndrome [29]. Humans get Cryptosporidium via the faecal-oral route, which includes direct person-to-person or animal-toperson contact, as well as consumption of contaminated food or water [29].

Mixed infection/polyparasitism was detected, and this agrees with the work of many researchers $[3,17,23,30]$. Multiple intestinal infections in children have been confirmed to be a natural occurrence triggered by the interaction of common environmental factors, modes of infection, host exposure, vulnerability, as well as behavioural and socioeconomic factors that promote the co-occurrence of various parasites [24]. Gender was not found to be a significant risk factor, both sexes were equally exposed $P>0.05$. This aligns with the work done in Osun State Nigeria, in Malaysia, and in Cameroun $[1,2,31]$ but at variance with what was reported in Abeokuta, southwest Nigeria and in Ebenebe, Anambra southeast Nigeria $[32,33]$ that reported a significant difference in boys. Significant difference in girls was reported in Oshodi Lagos, southwest Nigeria [5]. Intestinal parasitic infections in malnourished children in this work were not aged dependent $P>0.05$. This does not agree with the work of many researchers that 
reported age as a significant risk factor $[2,5,13,22,34]$. This disparity may have been due to the nutritional status of these patients that predisposed them to intestinal parasitic infections.

The higher prevalence of IPIs in Obiagu, this area is a typical slum where there is insufficient access to potable water, sanitation, and other infrastructure, as well as low housing quality, overcrowding, and insecure household characteristics.

Although several factors contribute to malnutrition, intestinal parasitic infections have been linked to stunted development [23].

\section{CONCLUSION}

The prevalence of IPIs in malnourished children was $51.8 \%$ and $12 \%$ in healthy control. Ascaris lumbricoides was the most prevalent helminths while Cryptosporidium spp. was the most prevalent protozoa. Mixed infections were detected in $3(7.5 \%)$ and $6(21.4 \%)$ of moderate and severe malnourished children respectively. Nutritional status was found to be a significant risk factor to IPIs while gender and age were statistically insignificant Anthropometry remains a useful tool for assessing the nutritional status of populations, particularly children in developing countries. The best predictor of a child's overall well-being is his or her nutritional status. Intestinal infections have been associated with malnutrition, based on this study. To disrupt the life cycles of STH disease, avoid reinfection, and achieve long-term control, annual therapies must be paired with macro/micronutrient supplements as well as health education. A well-fed population with a healthy immune system has a possibility of averting parasitic infection in the future.

Merely giving drugs to malnourished people, as is usual in the global fight against STHs, does not solve the problem; indigence and malnutrition must be considered if proposed MDA initiatives for NTDs are to be successful.

\section{CONSENT AND ETHICAL APPROVAL}

The protocol for this study was approved by the Ethics Committee of the University Of Nigeria. The parents/guardians were briefed on the purpose of the study and those who consented were given consent forms to sign and those who were not literate enough to sign were asked to thumb-print. They were assured of the confidentiality of their identities. They were also told that participation is voluntary. Children with no parental or guardian consent were excluded from the study.

\section{ACKNOWLEDGMENTS}

We thank all Paediatricians, dieticians, senior matrons, and all the staff of various hospitals and health centres that were used for this work. Special thank goes to the head of Department of Microbiology, University of Nigeria Teaching Hospital, Ituku/Ozalla Enugu for allowing us use their facilities. We thank all the children, caregivers/parents for their cooperation. The authors funded the research.

\section{COMPETING INTERESTS}

Authors have declared that no competing interests exist.

\section{REFERENCES}

1. Awolaju BA, Morenikeji OA. Prevalence and intensity of intestinal parasites in five communities in south-west Nigeria. Afr. J. Biotechnol. 2009;8(18):4542-4546.

Available:https://doi.org/10.5897/AJ2009.0 00-9421

2. Rajoo Y, Ambu S, Lim YA, Rajoo K, Tey SC, Lu CW, Ngui R. Neglected Intestinal Parasites Malnutrition and Associated Key Factors: A population based crosssectional study among indigenous communities in Sarawak, Malaysia. PLOS One. 2017;12(1):e0170174.

Available:https:doi.org/10.1371/journal.pon e.0170174

3. Feleke BE Nutritional Status and Intestinal Parasite in School Age Children; A Comparative Cross-Sectional Study. Int. J. Pediatr; 2016

Available:http://dx.doi.org/10.1155/2016/19 62128

4. Al-Delaimy AK, Al-Mekhlafi HM, Nasr NA, Sady $H$, Atroosh WM, Nashiry $M$, et al. Epidemiology of intestinal polyparasitism among Orang Asli school children in rural Malaysia. PLoS Negl Trop Dis. 2014;8(8):e3074-3087.

Available:doi.org/10.1371/journal.pntd.000 3074

5. Ajayi MB, Sani AH, Ezeugwu SMC, Afocha EE, Afesesan AA Intestinal parasite infction and body mass index among school children in Oshodi, Lagos Nigeria. 
Adv Cytol Pathol. 2017; 2(2): 44-49. Available:https://doi.org 10.15406/acp.217.02.00015

6. Roach RR. Soil-transmitted Helminths IntechOpen; 2020.

DOI:10.5772/intechopen.87143

7. Curtale F, Pezzoti P, Sharbini AL, Al Maadat $\mathrm{H}$, Ingrosso $\mathrm{P}$. Knowledge, perceptions and behavior of mothers towards intestinal helminths in upper Egypt: Implication for control. Health Policy Plan. 1998;13(4):423-432.

Available:doi.org/10.1093/heapol/13.4.423

8. Nokes C, Bundy DA. Does helminth infection affect mental processing and educational achievement? Parasitol Today. 1994;10(1):14-18.

Available: $\quad$ http://doi:10.1016/01694758(94)90348-4

9. WHO, Nutritional Landscape Information System, World Health Organization, Geneva, Switzerland; 2010.

10. Crompton DWT, Stephenson LS. Hookworm infection, nutritional status and productivity. In: Schad GA, Warren KS, editors. Hookworm disease: Current status and new directions. London: Taylor \& Francis; 1990.

11. Robertson LJ, Crompton DW, Sanjur D, Nesheim MC. Haemoglobin concentrations and concomitant infections of hookworm and Trichuris trichiura in Panamanian primary schoolchildren. Trans R Soc Trop Med Hyg. 1992;86(6):654-656.

Available:doi.org/10.1016/0035-

9203(92)90176-d.

PMID: 1287935

12. World Health Organization, Facts SheetMalnutrition.

Available:https://www.who.int/nesroom/fact-sheets/detail/malnutrition. Retrieved May $1^{\text {st }} 2020$

13. Ross AG, Papier K, Lucerres-Catubig R, Chau TN, Inobaya MT, Shu-Key N. Poverty, Dietary intake, Intestinal Parasites and Nutritional Status among School- Age Children in Rural Philippines. Trop. Med. Infect. Dis. 2017;2:49

Available:doi.org/10.3390/tropical/med204 0049

14. Jeremiah N, Carol A, Yulya S, Kacie M. Social and Economic Impact Review on Neglected Tropical Diseases Hudson Institute, Washington, DC, USA; 2012.

15. Hotez PJ, Fenwick A, Savioli L, Molyneux $\mathrm{DH}$. Rescuing the 'bottom billion' through control of neglected tropical diseases, The Lancet. 2009;373(9674):1570-1575.

Available:doi.org/10.1016/S0140-

6736(09)60233-6.

16. Nyaruhucha CN, Mamiro PS, Kerengi AJ, Shayo NB. Nutritional status of under-five children in a pastoral community in Simanjiro district, Tanzania, Tanzania Health Research Bulletin, 2006; 8(1):3236.

Available:https://doi:10.4314/thrb.v8i1.142 68

17. Hailegebriel T. Undernutrition, intestinal parasitic infection and associated risk factors among selected primary school children in Bahir Dar, Ethiopia. BMC Infect Dis. 2018;18:394.

Available: https://doi.org/10.1186/s12879018-3306-3

18. Cheesbrough, M District Laboratory Practice in Tropical Countries $2^{\text {nd }}$ Edition Updated, Part 1,; Cambridge University Press; 2009.

19. Gomez F, Galvan RR, Cravioto J, Frenk S. Malnutrition in Infancy and Childhood, with special reference to Kwashiokor. Adv. Pediatr. 1955;7:131-169.

20. World Health Organization (WHO). Deworming for health and development. Report of the Third Global Meeting of the Partners for parasitic control. World Health organization: Geneva, Switzerland; 2005.

21. Papier K, Williams GM, Luceres-Catubig $R$, Ahmed F, Olveda RM,McManus DP, Chy D, Chau TNP, Gray DJ, Ross AG, Childhood Malnutrition and Parasitic Helminth Interactions. Clin. Infect. Dis. 2014; 59(2): 234-243.

Available:https://doi.org/10.1093/cid/ciu211

22. Sidikiba, S, Alexandre D, Salim CB, Sidiki MA, Nirmal R, Habib BA Intestinal Parasitic Infections among Acute Malnourished children During Ebola at Ratoma Medical Centre of Conakry, Guinea. CAJPH. 2018;4(2):59-64.

Available:https://doi:10.11648/j.cajph.2918 0402.14

23. Opara KN, Udoidung N, Opara DC, Okon OE, Edosmwan UE, Impact of intestinal parasitic infections on the nutritional status of rural and urban school-age children in Nigeria. Int. J. MCH AIDS. 2012;1(1):6875.

Available: https://doi: 10.21106/ijma.8

24. Tsegaye B, Yoseph A, Beyene $H$. Prevalence and factors associated with intestinal parasites among children of age 
6 to 59 months in Boricha district, South Ethiopia, in 2018. BMC Pediatr. 2020; 20:28.

Available: https://doi.org/10.1186/s12887020-1935-3

25. WHO, Soil-transmitted helminth infections. Factsheet; 2017.

Available:http://www.who.int/mediacentre/f actsheets/fs366/en

26. Hamedi Y, Sofa O, Haidari M, Cryptosporidium infection in diarrheic children in Southern Iran. Pediatr Infect. Dis J. 2005;24(1):86-88.

Available:https://doi.org/10.1097/01.inf.000 0148932.68982.ec

27. Costa D, Razakadrain R, Valot S, Vannier M, Sautour M, Basmaciyan L Cryptosporidiosis in France from 2017 to 2019. Microorganisms. 2020;8(9): 1358.

Available:https://doi.org/10.3390/microorga nisms8091358.

28. Dawson DJ, Samuel CM, Scrannage V, Atherton CJ. Survival of Cryptosporidium species in environments relevant to foods and beverages. J. of Appl. Microbiol. 2004; 96(6):1222-1229.

Available:https:doi.org/10.1111/j.1365-

2672.2004.02281.x

29. Salehi Sangani G, Mirjalaki Rezaeian H, Farnia S, Rezaeian M. Prevalence of Intestinal coccidial infection among different Groups of Immunocompromised patients. Iran J. Parasitol. 2016;11(3):332338.

Available: http://ijpa.tums.ac.ir

30. Nkenaazong I, Njiokou F, Teukeng F, Enyong $\mathrm{P}$, Wanji S. Reassessment of endemicity level of urinary schistosomiasis and impact of mass drug administration (MDA) on the parasitic indices. J. Cell Anim. Biol. 2009;3(9):159-164.

http://www.academicjournals.org/JCAB

31. Okonko IO, Soleye FA, Amusan TA, Mejeha OK, Babalola ET, Adekolurejo OA. Detection and prevalence of intestinal parasites in patients in Abeokuta, SouthWest, Nigeria. World Appl. Sci. J. 2009;7(9);1183-1187.

32. Zonta ML, Cociancic $\mathrm{P}$, Oyhenart $\mathrm{EE}$, Navone G.T. Intestinal Parasitosis, undernutrition and socio-economic factors in school children from Clorinda Formosa, Argentina, Rev. Salud Publica. 2019;21(2):224-231.

33. Chukwuma MC, Ekejindu IM, Agbakoba MR, Ezeagwuna DA, Anaghalu IC, Nwosu DC. The Prevalence and Risk Factors of Geohelminth infections among primary school children in Ebenebe town, Anambra State, Nigeria. Middle-East J. Sci. Res. 2009;4(3):211-215.

34. World Health Organization. Iron deficiency anaemia. Assessment, prevention, and control. A guide for programme managers. Geneva: WHO; 2001.

(C) 2021 Onyemelukwe et al.; This is an Open Access article distributed under the terms of the Creative Commons Attribution License (http://creativecommons.org/licenses/by/4.0), which permits unrestricted use, distribution, and reproduction in any medium, provided the original work is properly cited. 